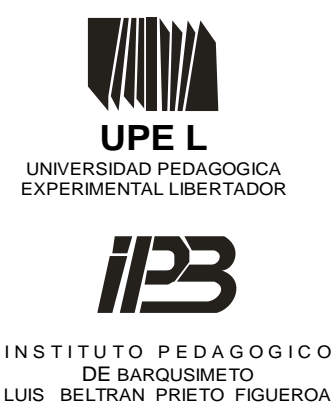

DE BARQUSIMETO
LUIS BELTRAN PRIETO FIGUEROA

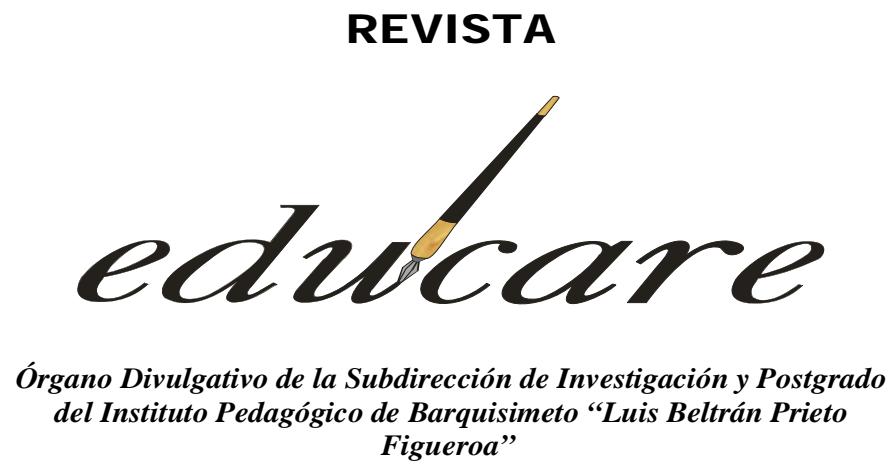

REVISTA

Figueroa"

BARQUISIMETO - EDO. LARA - VENEZUELA

NUEVA ETAPA

FORMATO ELECTRÓNICO

DEPOSITO LEGAL: ppi201002LA3674

Volumen $18 \mathrm{~N}^{\circ} 1$

ISSN: 2244-7296

\title{
FUNCIONES Y ACTITUDES DE LOS LÍDERES DE LA UNIVERSIDAD NACIONAL ABIERTA
}

FUNCTIONS AND ATTITUDES OF LEADERS FROM THE OPEN NATIONAL UNIVERSITY

\author{
Belcys M. Fumero G.* \\ Norma M. Caira T. ** \\ *UNIVERSIDAD NACIONAL ABIERTA (U.N.A.) \\ **UNIVERSIDAD DEL ZULIA (L.U.Z.)
}




\section{FUNCIONES Y ACTITUDES DE LOS LÍDERES DE LA UNIVERSIDAD NACIONAL ABIERTA \\ FUNCTIONS AND ATTITUDES OF LEADERS FROM THE OPEN NATIONAL UNIVERSITY}

TRABAJO DE INVESTIGACIÓN

Recibido:22-11-13

\section{Belcys M. Fumero G.}

UNA

Norma M. Caira T. **

LUZ

Aceptado: 23-03-14

\section{RESUMEN}

El presente artículo es resultado de una investigación documental enmarcada en el paradigma cualitativo donde pretendemos plantear algunas reflexiones sobre la ética compleja de Morín en el contexto educativo. Utilizamos la metodología hermenéutica. Analizamos e interpretamos bajo nuestra perspectiva subjetiva los diferentes elementos de la ética compleja en el contexto educativo. Finalmente, concluimos que la ética compleja también llamada de resistencia y de religación; es indispensable en la educación porque permite al hombre alejarse de la noción del mal elevando su dimensión altruista. Esta última, necesaria durante la formación educativa de todo ser humano, debido al acompañamiento que recibe de otros seres semejantes a él con los que debe compartir sus conocimientos, habilidades y valores como parte del orden social y planetario.

Descriptores: Ética compleja de religación o de resistencia, noción del mal y el bien, educación

\begin{abstract}
The present article resulted from a documental qualitative research in which we stated some ideas about Morín's complex ethics in the educational context. Hermeneutic methodology was followed. We analyzed and interpreted under our subjective perspective the different elements of complex ethics in the educational contexts. Finally, we concluded that complex ethics, also known as resistance ethics, is necessary because it lets mankind to get away from the idea of evil raising its altruist dimension. The latter is necessary during educative formation of every human beings due to the accompaniment they receive from others with which they should share their knowledge, abilities and values as part of the world and social order.
\end{abstract}

Keywords: complex resistance ethics, evil and good knowledge, education.

\footnotetext{
* Socióloga. Universidad Nacional Abierta, cursando actualmente Docencia para la Educación Universitaria en Universidad del Zulia - Facultad de Humanidades y Educación. E-mail: belcysf@gmail.com.

** Profesora Titular de la Universidad del Zulia. Socióloga. Msc. Gerencia de Empresas. Autora y Co-Autora de artículos arbitrados publicados en revistas nacionales e internacionales. Investigadora Acreditada al PEII. E-mail: normacaira@gmail.com.
} 


\section{INTRODUCCIÓN}

Una de las manifestaciones más claras del raciocinio del ser humano fue el abandono progresivo de su individualidad y la aceptación de la necesidad de su actuación colectiva. Esta reflexión lo llevó a pensar, actuar y vivir en forma de organización sustituyendo su primitiva conducta personalista. Esta actitud ha sido la creadora de distintas formas de organizaciones humanas, las cuales van desde la más simple como la familia, hasta las de mayor complejidad, como la conformación de una República, en cualquiera de los casos se presume la necesidad de alcanzar objetivos comunes en beneficio de todos quienes la integran.

De este último aspecto, referido al alcance del bienestar colectivo, surge la necesidad de darle a toda organización un sentido de direccionalidad para facilitar ese logro, requiriéndose de una uniformidad de criterio así como la selección clara de la mejor vía para alcanzarlo. Obviamente esto involucra la constante necesidad de tomar decisiones que la enrumben sobre el camino correcto, con las actuaciones y procesos oportunos, así como también el desarrollo de un sistema de autocrítica suficiente para entender los errores cometidos en todo el trayecto, enderezando comportamientos y actuaciones que le permitan a sus integrantes llegar de la manera más rápida, económica y segura a los objetivos planteados. De este importante requerimiento aparece la necesidad del liderazgo.

El liderazgo es definido por Robbins (2007) como un "proceso que consiste en influir en un grupo para orientarlos en el alcance de objetivos” (p.607). Esta responsabilidad asumida por el líder lo conduce a la obligación permanente de la toma de decisiones, que le permitan desde el punto de vista colectivo llegar donde ese grupo u organización necesita y quiere; además, desde el punto de vista individual, demostrarle a ese grupo y también a sí mismo, que dispone de la capacidad suficiente para continuar ejerciendo sus funciones.

Asimismo, las responsabilidades de quien ejerce el liderazgo lo llevan a poseer y desarrollar cualidades, actitudes y aptitudes especiales que lo diferencian del resto de los integrantes del grupo, pero en esto no puede existir un modelo ideal o estandarizado, pues ha de depender del tipo de grupo u organización que éste deba guiar.

El liderazgo ejercido en una organización familiar ha de ser distinto a una de carácter militar o una empresa de producción de bienes, dado que los objetivos, los procesos y las características de los seguidores, entre otras cosas, lo obligan a diferenciarse; por estas 
razones, desde hace algunas décadas se estudia la existencia de distintos estilos de liderazgo y su funcionalidad en cualquier institución bajo la perspectiva de diferentes teorías organizacionales.

Encontrar una definición exacta y única del liderazgo es una labor difícil, ya que ésta varía de acuerdo con la posición de los autores y la época donde se desarrolla. Al respecto han surgido diferentes postulados que generaron innumerables teorías que tratan de definir su significado.

Según Davis y Newstrom (2003), el liderazgo es el proceso de influir y apoyar a los demás para que trabajen entusiastamente a favor del cumplimiento de objetivos. Es decir, que "es el factor decisivo que contribuye a que los individuos o grupos identifiquen sus metas que después los motiven en el cumplimiento de los objetivos establecidos” (p.193). De acuerdo con Daft (2006) el liderazgo es “la relación de influencia que ocurre entre los líderes y sus seguidores, mediante la cual las dos partes pretenden llegar a cambios y resultados reales que reflejen los propósitos que comparten” (p. 5).

En el mismo contexto, Bateman y Snell (2001) consideran el liderazgo como la capacidad de conocer a los demás, evaluar situaciones y seleccionar los comportamientos que requieran los cambios para responder con mayor efectividad a los requerimientos de los acontecimientos. Por su parte, Lussier y Achua (2011) definen el liderazgo como el “proceso de influencia de líderes y seguidores para alcanzar los objetivos de la organización mediante el cambio” (p. 6).

Dado que las organizaciones tienen la tendencia a desarrollar líderes, gente con habilidad para influir en otros, es difícil imaginarse cumplir con las metas trazadas en las mismas si no hubieran individuos con la autoridad y responsabilidad necesarias para planear, organizar, coordinar, dirigir y controlar las actividades de las mismas. En este sentido, se asume que el liderazgo es el proceso de influencia entre líderes y seguidores que busca organizar a un grupo de individuos, procurando elevar su entusiasmo a nivel laboral con el propósito de alcanzar los objetivos de la institución.

Respecto a las teorías organizacionales, se retoma el planteamiento de Simon (1947) cuando señala, cuestionando la teoría racional de las organizaciones, que el ser humano tiene un conocimiento fragmentario de las condiciones que rodean su acción y sus consecuencias, lo cual denota una racionalidad limitada. Seguidamente, March y Simon 
(1958) exponen que las personas tienden a no buscar una solución óptima considerando límites de tiempo, la capacidad de tratar la información, la organización y utilización de su memoria, sino que de manera consciente o inconsciente aceptan una solución satisfactoria, mas no óptima.

Los criterios de satisfacción que se ponen de manifiesto dependen de los valores y de la percepción de la realidad que ellos tienen, ante lo cual la toma de decisión se ve restringida por estas características del ser humano. Esta situación hace que Simon (ob. cit) caracterice la organización como un sistema de decisiones, de forma tal que en una situación compleja, los individuos reducen la incertidumbre simplificando los datos del problema, estableciendo límites o fronteras a la racionalidad de las decisiones favorecidas por las prácticas y los hábitos, asegurando su permanencia en la organización a la que pertenece.

Esta limitación de la racionalidad y la búsqueda de permanencia en una organización, se traduce en lo que March y Simon (ob. cit) denominaron sistema flojamente acoplado, al relacionar la estructura jerárquica con los programas de acción individual de una organización, con el siguiente resultado: los actores de racionalidad limitada conducen a un proceso de descomposición del todo complejo, una especie de simplificación organizacional que hace vislumbrarlo como un sistema laxo.

En este contexto se ubican las organizaciones educativas en general, y en particular las vinculadas a la educación superior. Éstas poseen características muy propias que les permiten diferenciarse de otras, pues en ellas han de combinarse necesidades de formación académica de los individuos bajo distintas premisas e ideologías, así como en diversos campos de la ciencia y el conocimiento; no escapando de ello las instituciones vinculadas con la educación a distancia, cuyo origen en los países latinoamericanos logró responder a las necesidades de la población a nivel educativo, constituyéndose desde entonces en una herramienta de promoción social de gran valor.

Al observar aspectos de esa educación a distancia, en el caso venezolano, se percibe que tuvo su mayor presencia a través de la Universidad Nacional Abierta (UNA), creada por el Ejecutivo Nacional, según decreto No 2398 del año 1977, como una Institución Experimental de Educación Superior, organizada para impartir educación a distancia, conformada por 22 Centros Locales y 46 Oficinas de Apoyo, repartidos por toda la 
geografía nacional, que constituyen las unidades de ejecución de sus programas, siendo el nivel operacional básico de gran relevancia al constituir el órgano inmediato de relación directa con los estudiantes. Su carácter de universidad experimental restringe su autonomía y la hace dependiente del gobierno nacional.

Por las características de su organización y la dinámica de su funcionamiento, la Universidad Nacional Abierta posee una modalidad en la forma de impartir el conocimiento en todas sus carreras con visos distintos a la educación superior tradicional, pues desde su fundación hace más de treinta años, se diseminó por todo el país, constituyéndose como la única universidad venezolana con esas particularidades. Constituye un sistema de educación abierta y a distancia (SEAD), siendo la única universidad venezolana cuya oferta académica total es no presencial (lo que se conoce como universidad unimodal), hecho que no la exime de la problemática del sector.

Tomando como base el resultado de una auditoría realizada a la institución sobre su desempeño tanto interno como externo, se detectó que existen algunas debilidades y amenazas que pudiesen entorpecer un proceso gubernamental de desarrollo organizacional de la misma como alternativa educativa viable. Entre esas debilidades se observó que hay poca sensibilidad ante las señales de su entorno (dentro y fuera de ella), ausencia de programas de desarrollo profesional, débil imagen pública, debilidad en el proceso de comunicación organizacional y entre sus amenazas, desarticulación de las políticas internas y las políticas del Estado, aunado esto a una mayor asignación presupuestaria proporcional a otras universidades con menor alcance.

Esta situación invita a razonar sobre los procesos que pueden darse en su interior, aunque sea un caso específico de organización universitaria, en función de que, siendo dependiente del poder gubernamental central, su carácter experimental y restricción autonómica contribuyen al desconocimiento de su operatividad interna respecto a la actuación de sus líderes, concretamente en referencia a las funciones y actitudes asumidas por ellos.

Dado que parte de esta situación recae en su personal, cabe destacar que la Universidad Nacional Abierta cuenta con un personal administrativo que realiza las actividades organizacionales de apoyo comunes con aquellas que se realizan en otras universidades oficiales, es decir, actividades vinculadas con presupuesto, finanzas, 
compras, recursos humanos y servicios. No obstante, dada su condición de universidad a distancia, ese personal administrativo apoya al mismo tiempo dos de las más distintivas funciones medulares de la Educación a Distancia, como son las de producción y distribución de materiales de instrucción impresos, audiovisuales y telemáticos (profesionales, técnicos y de apoyo), de manera que su actuación redunda en la percepción que se tenga sobre la institución.

De acuerdo con observaciones realizadas en la Unidades Operativas de la institución seleccionada, la Universidad Nacional Abierta presenta diferencias que afectan su relación con los recursos humanos, destacándose problemas a nivel de comunicación y motivación, caracterizados por la centralización y estandarización en la forma de dirigir este centro universitario, lo cual coadyuva a la presencia de señales de su carácter de sistema flojamente acoplado (March y Simon, ob. cit).

Para Cohen y March (1974), luego de estudios sobre organizaciones universitarias, se amplía ese concepto a anarquías organizadas, contextualizando la toma de decisiones en las universidades en tres aspectos: fuerte ambigüedad de preferencias, tecnología indeterminada o poco dominada y fluida participación en procesos decisionales. De esta manera, se ratifica la descripción de estas instituciones como débilmente cohesionadas, con fragmentación de tareas y alta rotación de participantes, entre otras.

Debido a esta percepción preliminar, se consideró de interés analizar las funciones y la actitud de los líderes de las Unidades Operativas del Centro Local Zulia de la Universidad Nacional Abierta, con la finalidad de que estos resultados coadyuven al mejoramiento de los niveles de competitividad y productividad tan reclamados en este medio, comprometido con la realidad, con la capacidad de convocatoria para dar respuesta, unificar voluntades y de esta forma promover el liderazgo en pro de la organización. Entre los aspectos de interés a considerar para acometer la presente investigación, destacan la importancia que dentro de la teoría organizacional se le atribuye al liderazgo como factor capaz de facilitar y/o restringir el logro de los objetivos organizacionales. 


\section{FUNDAMENTACIÓN TEÓRICA}

\section{Funciones del Líder}

Al revisar la literatura sobre este aspecto, cabe retomar la postura de Mintzberg (1991), quien expone que los líderes cumplen tres tipos de papeles: interpersonales, informativos y decisorios, los cuales son retomados y definidos por Da Silva (2003) como "los conjuntos de expectativas sobre el comportamiento de un administrador en situaciones específicas”(p. 16).

Se visualiza así la vigencia de la postura de Mintzberg (1991), para quien los papeles interpersonales derivan de la autoridad formal, lo cual conlleva al cumplimiento de deberes ceremoniales, así como actividades rutinarias con poca información seria y toma de decisiones que a pesar de poder ser consideradas de escasa importancia, tienen su peso en el buen funcionamiento organizacional, por lo que no deben ser ignoradas.

En este sentido, es responsable del trabajo de las personas a su cargo, lo cual incluye motivar y animar a los empleados, procurando equilibrar sus necesidades individuales con los objetivos organizacionales. Como líder, el directivo goza de una autoridad formal que le otorga poder, lo que esa persona debe decidir es en qué cantidad lo utilizará.

Al respecto, Da Silva (ob. cit) acota que los papeles interpersonales constituyen funciones desempeñadas para relacionarse e interactuar con otras personas y que pueden ser tres: Jefe: cuando el administrador se coloca como representante de la organización en lo que se refiere a los principios, la misión, los objetivos; Líder: cuando contrata, motiva a los empleados y regula el proceso de comportamiento del equipo; Nexo: cuando cubre ese rol participa regularmente en el trato con personas externas a la organización, para alcanzar los objetivos de ésta.

Los papeles informativos implican su rol de informar y satisfacer a las personas influyentes que tienen control sobre su unidad organizativa, pudiendo fungir como monitor, difusor o portavoz (Mintzberg, ob. cit). Los mismos conforman roles desempeñados para intercambiar y procesar información, de esta manera el directivo debe desempeñar también tres papeles fundamentales: Monitor: el directivo vigila activamente el contexto para obtener información relevante para el desempeño de la organización; Diseminador: cuando cuenta con información importante, recogida del contexto y la trasmite a las personas 
adecuadas de la organización. Interlocutor: en nombre de la empresa distribuye la información de importancia y/o respuestas recibidas (Da Silva, ob.cit.).

Referente a los papeles decisorios, Mintzberg (ob.cit.), retomado y complementado por Da Silva (ob.cit.), expone que el directivo desarrolla un papel de peso en su sistema de toma de decisiones, pudiendo expresarse como empresario o emprendedor (busca adaptar su unidad a las condiciones cambiantes del entorno, considerando las oportunidades que se presenten), gestor de anomalías o solucionador de conflictos (responde involuntariamente a las presiones, resolviendo conflictos internos o externos de la organización), asignador o distribuidor de recursos (diseña estructura de su unidad, determina cómo serán distribuidos el dinero, el equipo, las instalaciones y los recursos entre las diversas áreas de la institución) y negociador (consigna recursos organizativos en tiempo real, procurando llegar a acuerdos y contratos que beneficien a la organización), dado que, como autoridad formal, sólo él está en capacidad de hacer seguir nuevos cursos de acción al contarse como el único que posee información completa y actualizada para tomar las decisiones que determinen el rumbo o estrategia que habrá de seguir su unidad.

Bajo este contexto, cuando se habla de liderazgo la referencia inmediata se hace hacia sus funciones, dado que éstas le permitirán al directivo o líder un buen desempeño en la relación con sus seguidores y, por consiguiente, en la creación de equipos efectivos de trabajo. En este sentido, se asume la propuesta de Madrigal (2002), quien propone cuatro funciones, las cuales considera esenciales para el desarrollo de un líder: comunicar, integrar, motivar y delegar, que de una u otra forma se relacionan con las funciones enumeradas anteriormente.

Respecto a la comunicación, plantea que el líder debe saber comunicarse con sus seguidores y detenerse para cerciorarse que se entendió su mensaje; entendiéndose esta función como un proceso que se da entre dos personas con el objetivo fundamental de trasmitir y recibir un mensaje. La comunicación de un líder debe ser efectiva, es decir, que la información llegue a quien está dirigida y cumpla su objetivo, para que de esta forma pueda influir sobre sus seguidores, siendo definida por Lussier y Achua (ob. cit) como "el proceso que consiste en trasmitir información y significado"(p.174), enfatizando que la verdadera comunicación se da cuando las partes que intervienen en el proceso entienden el mensaje desde el mismo punto de vista. 
Dada esta perspectiva, es importante resaltar que la comunicación eficaz es una de las capacidades más fundamentales del líder, ya que estudios reflejan que los buenos líderes también son comunicadores eficaces, estableciendo así una estrecha relación entre la capacidad de comunicación y el desempeño de ese líder. De acuerdo con Lussier y Achua (ob. cit) impera un proceso de trasmisión de mensajes orales que está conformado por cinco pasos esenciales: generar confianza; definir el objetivo de comunicación; trasmitir el mensaje; verificar que el receptor ha entendido y lograr el compromiso del receptor, al cual debe darle seguimiento.

Complementando lo anterior, se visualiza que la comunicación del líder incluye enviar, recibir y retroalimentar información, muchas veces de manera general, en lugar de hechos aislados o fragmentados, razón por la cual se dice que un líder es un as de la comunicación. Como acota Daft (ob. cit), un campeón de la comunicación es una “persona cuyos principios filosóficos sientan las bases de la creencia en que la comunicación es esencial para crear la confianza de las personas y para conseguir que se comprometan con una visión” (p. 350).

Los líderes usan la comunicación para inspirar y unir a las personas en torno a un sentimiento común de identidad y propósito. El aprendizaje, la resolución de problemas, la toma de decisiones y la formulación de estrategias están orientados hacia esa visión y se derivan de ella. La comunicación no es sólo cuestión de juntas ocasionales, de discursos formales o de presentaciones, es la forma activa para entablar relaciones personales con los seguidores.

Cuando los líderes establecen un clima de comunicación abierta, escuchan activamente a otros, aprenden a discernir mensajes subyacentes y recurren a la práctica del diálogo, facilitan y apoyan conversaciones estratégicas que ayudan a que la organización avance. En este sentido, logran emplear diversos métodos de comunicación, pudiendo seleccionar canales de comunicación con mucho potencial, usar relatos y metáforas o recurrir a la comunicación informal. Es así como los líderes facilitan las conversaciones estratégicas cuando escuchan activamente a otros para comprender sus actitudes y valores, necesidades, metas personales y deseos; establecen la agenda de la conversación subrayando los temas estratégicos claves vinculados con el éxito de la organización y seleccionan los canales de comunicación adecuados facilitando el diálogo. 
En cuanto a la integración, la idea es atender más el factor humano. El líder debe procurar integrar los recursos humanos, técnicos y materiales de la organización. Según Schermerhorn (2010) es el "nivel de coordinación alcanzado entre los componentes internos de una organización” (p. 229). Constituye una función a través de la cual los líderes eligen y se rodean de los recursos necesarios para poner en marcha las decisiones previamente establecidas para ejecutar los planes, incluyendo los recursos tanto materiales como humanos.

Esta función parte de tres principios: 1) El hombre adecuado para el puesto adecuado: los hombres deben poseer las características que la empresa establezca para desempeñar un puesto. Los recursos humanos deben adaptarse a las características de la organización y no ésta a ellos; 2) Provisión de los elementos necesarios: la dirección debe estar consciente de los elementos que los puestos requieren para la eficiente realización de su trabajo, debe dotarse a cada miembro de la organización, de los elementos administrativos necesarios para hacer frente en forma eficiente a las obligaciones del puesto; 3) La importancia de la inducción adecuada: el ingreso del recurso humano es transcendental, pues de él dependerá su adaptación al ambiente de la empresa, su desenvolvimiento, su desarrollo y su eficiencia dentro de la misma.

Referente a la motivación, todo líder es motivador: éste hace que los otros hagan. En consecuencia, debe entender por qué actúa la gente y saber manejar con destreza esos resortes, es decir, las motivaciones que llevan a una persona a proceder de una forma u otra. También debe saber cuándo motivarla para que siga adelante.

La motivación es una de las habilidades que el líder moderno ha desarrollado y debe seguir desarrollando, dado que refuerza el trabajo de las personas hacia un mismo fin, el cual incluye sus propios objetivos, por lo que cabe destacar la importancia que la motivación interna cobra paulatinamente.

Al respecto, Lussier y Achua (ob. cit) expresan que es "todo aquello que influye en el comportamiento cuando se busca obtener cierto resultado” (p. 74). Todo líder espera influir sobre sus seguidores y una forma de hacerlo es motivándolo para el logro de los objetivos organizacionales. Por lo tanto, su habilidad para motivarse a sí mismo y a sus seguidores es fundamental para rendir buenos frutos como líder. 
Los motivos no se pueden observar, pero el comportamiento sí y se puede inferir qué motivó a una persona. De acuerdo con esto, no hay una sola teoría que indique la forma de motivar a la gente, pero existen algunas que tratan de describir esta función, como la teoría del proceso de motivación, la teoría del contenido de la motivación y la teoría del reforzamiento, entre otras. Como acotan Lussier y Achua (ob. cit), existe un proceso de motivación "donde la gente pasa de la necesidad de motivar un comportamiento para lograr la satisfacción o insatisfacción”(p. 74). Exponen que la teoría del proceso de la motivación intenta entender la forma en que los empleados eligen satisfacer sus necesidades.

Según estos autores existe una teoría de reforzamiento, en la cual exponen que el comportamiento puede explicarse, predecirse y controlarse mediante las consecuencias de la conducta. Para ello hay varios tipos de reforzamiento, como el positivo, el negativo, la extinción y el castigo.

Por otra parte, al describir la delegación, Madrigal (ob. cit) expone que el líder que delega confianza en sí mismo y en su gente, sabe compartir la responsabilidad y el poder. Complementan este enfoque Lussier y Achua (ob. cit) al definir esta función como "un proceso que consiste en asignar responsabilidad y autoridad a alguien para la consecución de objetivos” (p.245). Pedirle a los seguidores que lleven a cabo tareas que forman parte de su trabajo es comunicar órdenes, no delegar. Delegar es asignar nuevas tareas a los empleados, las cuales constituyen un rediseño de actividades o simplemente constar de una tarea única.

La delegación exitosa se basa a menudo en elegir qué tarea delegar y en quién hacerlo, tiene una serie de beneficios, como tiempo para realizar tareas prioritarias, permitir que las tareas se cumplan y aumentar la productividad, a la vez que se prepara a los empleados y se le sube la autoestima, además que se alivia la tensión y la carga de trabajo. Se trata de desarrollar a los seguidores enriqueciendo su trabajo. En suma, la delegación puede dar como resultado un mayor desempeño y mejores resultados laborales.

En algunos casos, los directivos consideran que sólo ellos pueden realizar el trabajo en forma más eficiente que los demás, olvidando que la delegación es parte importante de su labor, otros no saben qué delegar y algunos más no saben hacerlo. Un líder puede delegar cualquier tarea donde no tenga que participar por ser el único que posee las habilidades y el conocimiento para realizarlas. Lo que no se debe delegar son actividades 
donde tenga que participar de manera directa por tener los conocimientos y capacidad para realizarlos. Para determinar en quien delegar, se debe asegurar de que cuenta con la capacidad para llevar a buen término la labor asignada en el tiempo establecido. Es importante considerar los talentos e intereses de los seguidores para seleccionar aquel que represente y supere las expectativas que se tienen.

\section{Actitud del Líder}

Una actitud es la consecuencia de los valores y normas que la preceden, a su vez es una tendencia evaluadora positiva o negativa con respecto a las personas, hechos o cosas. Las actitudes reflejan cómo se siente cada individuo con respecto a algo o a alguien y predice su tendencia a actuar de una manera determinada, dentro de un contexto específico (Daft, ob. cit).

La actitud del líder es un factor determinante en la formación de la cultura de la organización, pero también en el cultivo de unas sólidas relaciones interpersonales que necesitan motivación y un trato humano cordial y generoso. Por tanto, se requieren de líderes amables, respetuosos y abiertos a los demás.

El alto desempeño de un líder no está relacionado sólo con tener sólidos conocimientos académicos, aptitudes para ejercer un determinado cargo, sino también actitudes que ejerzan influencia en el comportamiento y en el desempeño de sus seguidores. Ser líder, más que ciencia es un arte que debe saberse conquistar con un aprendizaje continuo y con la iniciativa para proponer cambios necesarios, que debe ir acompañada de un orden que sistematice su ejecución y evaluación respectiva, pues no se trata de plantear intenciones temporales sino que perduren en el tiempo y que tenga efectos positivos en quienes laboran en la empresa.

Desafortunadamente, existen muchas causas por las cuales un empleado no se siente satisfecho en su sitio de trabajo. Algunas personas optan por aceptar un puesto sólo porque no encontraron algo mejor en donde pudieran desarrollar la profesión que estudiaron, porque la situación no les da la posibilidad de cambiar. Asimismo, se nota inconformidad cuando el ambiente organizacional no es el adecuado o los compañeros, los directivos y los supervisores no son del todo agradables. 
Los líderes con actitudes negativas muestran un estilo de liderazgo coercitivo y autocrático, recurren a métodos de control como amenazas y castigos. Este enfoque puede lograr un desempeño aceptable en ocasiones pero tiene un alto costo, ya que a los empleados les disgusta el trabajo y hay que supervisarlos continuamente.

En este sentido, los líderes de toda institución u organización tienen mucha influencia en el desempeño de sus seguidores. Tal influencia puede ser negativa o positiva dependiendo de las expectativas que tenga el líder sobre el personal seguidor.

Lo anteriormente expuesto permite presentar algunos conceptos y teorías que presentan la posibilidad de ordenar las relaciones para el beneficio de las organizaciones. Existen patrones de comportamiento que son índices de la relativa salud o enfermedad de una organización, tal es el caso de la Teoría de X y Teoría Y de McGregor y el Efecto Pigmalión, retomados por Daft (ob. cit) en su teorización, que analizan cómo influyen las actitudes del líder hacia sí mismo y hacia sus seguidores, así como la manera de identificar las conductas que afectan los estilos de liderazgo.

Respecto a estas Teorías X e Y, Lussier y Achua (ob. cit), tratan de explicar y predecir el comportamiento y el desempeño con base en la actitud del líder hacia sus seguidores. Los líderes que tienen actitudes hacia la teoría " $\mathrm{X}$ " sostiene que los empleados sienten un desagrado natural hacia el trabajo, debido a esto, hay que obligarlos, controlarlos, dirigirlos y amenazarlos para lograr que pongan suficiente esfuerzo en la obtención de los objetivos organizacionales.

El liderazgo con estas características ha de estar basado en el ejercicio de una autoridad formal, donde se señala a cada uno lo que debe hacer y cómo hacerlo, marca los tiempos de realización del trabajo, dicta unas normas a seguir y somete a los empleados a una constante presión, consiguiendo que hagan los esfuerzos necesarios para evitar ser sancionados, correspondiendo estas actuaciones a un estilo de dirección autoritario.

Respecto a las actitudes hacia la teoría "Y”, consideran que los empleados practicarán la autodirección y el control de sí mismas en vista de los objetivos planteados, el trabajo puede ser fuente de realización y se efectuará voluntariamente. La supervisión continua y el castigo no son los únicos medios para el logro de los objetivos de la organización. Según estos supuestos, el papel del líder es desarrollar el potencial de sus seguidores y ayudarles a que logren las tareas en beneficio de los objetivos comunes. 
Por otra parte, referente al Efecto Pigmalión, los empleados responden de acuerdo a como sean las expectativas de sus supervisores. En las organizaciones el efecto Pigmalión se puede definir como las consecuencias que generan sobre el comportamiento de un empleado las expectativas y creencias que se tienen de ella. Si siente que se le valora poco o que es tratado con desconfianza, esto se reflejará en sus acciones posteriores, mostrando resultados mediocres. Si, por el contrario, percibe que sobre ella se deposita confianza y se le trata con consideración, su desempeño mejorará notablemente.

Al respecto, Lussier y Achua (ob. cit) acotan que el líder "propone que las actitudes de los líderes hacia sus seguidores, las expectativas de éstos y el trato que le dan, explican y predicen su comportamiento y desempeño” (p. 45). Es por esto que los responsables de equipos, aquellos que tienen gente a su cargo, deben de ser conscientes de su existencia y de las posibilidades que ofrece.

Por su parte, Saracho (2005) expresa que la actitud es una forma de percibir el entorno de manera estable y duradera, que se manifiesta en un determinado modo de actuar o comportarse ante un objeto, persona o grupo de ellas. Esta forma de percepción del entorno se adquiere (no es innata), lo que significa que, al ser receptiva o positiva, exterioriza una predisposición a atender (escuchar) atentamente las opiniones de otros; pero al ser negativa o prejuiciosa, implica una tendencia a discriminar a algunas personas.

A esto agrega este autor (Saracho, ob. cit) que la actitud depende de dos factores determinantes, uno individual y otro social. Los factores individuales se vinculan con la creencia de que el comportamiento conduce a ganancias, pérdidas o reconocimientos como resultados de la acción; mientras que los factores sociales se conforman tanto de la valoración que el individuo hace de esos resultados en términos de buenos, malos, placenteros, beneficiosos, deseables, como de la percepción de lo que otros (grupo de referencia, jefe, por ejemplo) creen que el individuo debe hacer y de la motivación que tenga la persona para cumplir o no con lo que esos otros significativos creen que deben hacer.

En las organizaciones no se ha comprendido totalmente la importancia que tienen las expectativas de los líderes sobre las actuaciones individuales y de grupo, el papel de Pigmalión de un líder efectivo se caracteriza por su habilidad para crear la expectativa de un comportamiento de alto nivel, que efectivamente realizan sus seguidores. Los líderes 
menos efectivos no son capaces de desarrollar expectativas similares, y como consecuencia, sufren la improductividad de sus empleados o seguidores.

Los líderes positivos deben combatir los estereotipos negativos acerca de los empleados, olvidar resultados no exitosos, y definir objetivos desafiantes para los individuos y departamentos. La mayoría de las veces, los empleados o seguidores hacen lo que creen que se espera de ellos.

\section{METODOLOGÍA}

Se definió el estudio como descriptivo, no experimental, transeccional y de campo (Hernández, Fernández y Baptista, 2010; Tamayo, 2003; Chávez, 2007), siendo aplicada en las instalaciones de las Unidades Operativas del Centro Local Zulia de la Universidad Nacional Abierta, quedando constituida la población por los Jefes de Unidad (catalogados como los líderes de la organización para efectos de este estudio), el personal administrativo y docentes que laboran en las diversas Unidades Operativas del Centro Local Zulia de la Universidad Nacional Abierta, como se muestra en el Cuadro 1. Dado su número y accesibilidad, se realizó un censo poblacional.

Una vez seleccionado el diseño de investigación, se procedió a desarrollar la siguiente etapa, consistente en recolectar los datos sobre los atributos, conceptos, cualidades o variables de los casos, sucesos u objetos involucrados en la investigación. En este sentido, se eligió la observación mediante encuesta, procedimiento que consiste en la obtención de datos de interés sociológico mediante la interrogación a los miembros de la sociedad, y el más empleado en la realidad. Para su ejecución, se adoptó la propuesta de Sierra Bravo (1999), quien presenta como instrumento básico de la observación por encuesta el cuestionario.

\section{Cuadro 1.}

Población

\begin{tabular}{clc}
\hline \multicolumn{1}{c}{ Personal } & \multicolumn{1}{c}{ Cargo } & Cantidad \\
\hline & $\begin{array}{l}\text { Coordinador del Centro Local } \\
\text { Coordinador Académico } \\
\text { Jefes de Unidad }\end{array}$ & $\begin{array}{l}\text { Registro y Control de Estudio } \\
\text { Biblioteca } \\
\text { Administración } \\
\text { Computación }\end{array}$ \\
\hline Personal & $\begin{array}{l}\text { Administrativo } \\
\text { Docentes } \quad \text { Total }\end{array}$ & 4 \\
\hline
\end{tabular}


De esta manera, se diseñaron y aplicaron dos cuestionarios a la población seleccionada, distinguida por Jefes de Unidad que fungen como directivos, incluyendo personal docente y administrativo que desempeña funciones de empleados en la institución, los cuales permitieron precisar el comportamiento de la variable objeto de estudio. Los cuestionarios fueron revisados (validados) por expertos en el área para luego proceder a aplicar una prueba piloto, a fin de estimar su confiabilidad.

Dadas las características de los cuestionarios, uno dicotómico y otro conformado por cinco opciones de respuesta (Acuerdo - Desacuerdo), se utilizaron para la valoración de su confiabilidad las fórmulas de las dos mitades y Alpha de Cronbach, respectivamente, propuestas por Chávez (ob. cit) y estimadas mediante el Programa Estadístico SPSS 19, obteniéndose los siguientes resultados:

\section{Cuadro 2}

\section{Confiabilidad de los Cuestionarios}

\begin{tabular}{ccc}
\hline Cuestionario & Coeficiente & Interpretación \\
\hline A (Jefes) & 0.994 & Muy Alto \\
\hline B (Empleados) & 0.992 & Muy Alto
\end{tabular}

Como se observa en el cuadro anterior, al aplicar la fórmula se obtuvo como resultado un coeficiente de confiabilidad de 0.99 , considerándose como un valor muy alto, según el baremo propuesto adaptado del presentado por Palella y Martins (2010), por lo cual se procedió a la aplicación definitiva de ambos instrumentos (Ver Cuadros 2 y 3).

\section{Cuadro 3}

Baremo para la Interpretación de la Confiabilidad

\begin{tabular}{cc}
\hline Rango & Interpretación \\
\hline $0.81-1.00$ & Muy Alta \\
$0.61-0.80$ & Alta \\
$0.41-0.60$ & Media \\
$0.21-0.40$ & Baja \\
$0.01-0.20$ & Muy Baja \\
\hline
\end{tabular}

Fuente: Adaptación de Palella y Martins (ob. cit). 


\section{RESULTADOS}

Previo a la presentación de los resultados sobre las funciones y actitudes del líder observadas en el estudio, cabe acotar que se determinó que el liderazgo asumido por los Jefes de las Unidades Operativas no está conferido a un estilo de liderazgo en particular; de hecho, cada actor asume un liderazgo propio de acuerdo con sus competencias e ideales, siendo el más visible el estilo centrado en los empleados, señalización que se hace en función de haberse evidenciado que el personal directivo en su mayoría, manifiesta interés en el crecimiento personal, en resolver las necesidades y en propiciar una relación de confianza entre los empleados; sin embargo, en ocasiones imponen las funciones, así como también indicaron que algunas veces son los únicos que pueden tomar las decisiones, exigiendo el cumplimiento de las mismas, todo lo cual valida la teoría que al respecto se desarrolló con anterioridad.

De esta manera, en referencia a las funciones que cumplen estos líderes en el Centro Local Zulia de la Universidad Nacional Abierta, se obtuvo la siguiente información. Respecto a la función comunicación, los empleados manifestaron que los jefes saben comunicarse con ellos, trasmiten la información proveniente de niveles superiores, informan mediante memorando las posibles decisiones y cambios en el Centro Local y se esfuerzan para que la información llegue a todos los niveles de la institución. Por su parte, los jefes expresaron que publican información relacionada con el desempeño de la organización y se esfuerzan para que la información llegue a todos los niveles de la organización de forma oportuna.

En cuanto a la integración, los empleados expresaron que los jefes se preocupan por integrar los recursos humanos, técnicos y materiales para lograr las metas establecidas, es decir, que los jefes trabajan en pro de la integración de los recursos humanos dentro de la institución. Correspondiendo a esta perspectiva, los jefes se dividieron entre quienes consideran que su equipo de trabajo está totalmente integrado, y aquellos que señalan lo contrario; en lo que si concuerdan es en afirmar que se preocupan por integrar los recursos humanos, técnicos y materiales de la organización. Esto permite aseverar la manifestación de su característica de sistema flojamente acoplado.

Sobre la motivación, el personal universitario manifiesta que los jefes lo motivan a trabajar para alcanzar los objetivos de la institución y se preocupan por ayudar a los 
empleados en la resolución de problemas; esto lo ratifican los jefes, añadiendo que también aportan posibles soluciones a problemas cotidianos dentro de la organización.

Referente a la función de delegación, los empleados reflexionan que los jefes confieren a los empleados autoridad para que ejerzan el control sobre su trabajo, a la vez que les otorgan autoridad para tomar decisiones. Al respecto, los jefes encuestados afirmaron que brindan suficiente libertad a sus colaboradores para que desempeñen labores bajo su propio criterio.

De esta manera, al generalizar el resultado sobre las funciones del líder, se constató que respecto a la comunicación, los jefes trasmiten información de niveles superiores y saben comunicarse con los empleados, preocupándose por hacer llegar la información a todos los niveles de la institución. En relación con la función de integración, las respuestas de los empleados ponen en evidencia la preocupación de los jefes por integrar los recursos humanos, técnicos y materiales para lograr las metas. En este sentido, los empleados coinciden al afirmar que los jefes los motivan a alcanzar los objetivos organizacionales y se esmeran por ayudarlos. Así mismo, se puede observar que confieren autoridad para que ejerzan el control sobre su trabajo, sin llegar a observarse un grado muy significativo de otorgamiento de la misma.

Estos planteamientos coinciden con lo planteado por Lussier y Achua (ob. cit), Madrigal (ob. cit) y Schermerhorn (ob. cit) al señalar que el líder no puede dejar de hacer referencia a sus funciones, puesto que ellas posibilitan un buen desempeño en la relación con sus seguidores y por consiguiente a la creación de equipos efectivos de trabajo. Esta situación valida igualmente los supuestos teóricos de Mintzberg (ob. cit) y Da Silva (ob. cit) en lo concerniente a los papeles interpersonales, informativos y decisorios que cumplen los directivos dentro de una organización.

Así mismo, al observarse que los directivos de la institución confieren al personal autoridad para que ejerzan el control sobre su trabajo, sin llegar a observarse un grado muy significativo de otorgamiento de la misma, se confirma el planteamiento de March y Simon (ob. cit) cuando exponen que las personas tienden a no buscar una solución óptima considerando límites de tiempo, la capacidad de tratar la información, la organización y utilización de su memoria, sino que de manera consciente o inconsciente aceptan una 
solución satisfactoria, mas no óptima, poniendo nuevamente de manifiesto el carácter laxo de las instituciones de educación universitaria.

En cuanto a la actitud, los encuestados expresaron que los jefes mantienen una relación adecuada con el grupo y buscan ajustarse a cualquier circunstancia que se presente en el trabajo. Así mismo, los empleados manifestaron que los jefes trasmiten confianza a los empleados y manifiestan seguridad en sus capacidades para el logro de los objetivos; parte de ellos prefirió no concretar su opinión ante la pregunta referida a la influencia que los jefes puedan ejercer sobre su forma de actuar, en tanto una proporción menor aseveró que esa influencia sí se hace presente; en lo que coincidieron fue en aceptar que establecen normas y tiempo para la realización de actividades.

Por su parte, los jefes consideran que ejercen una influencia positiva sobre el desempeño de sus empleados; afirmando, igualmente, que los miembros de su equipo poseen altos niveles de desempeño laboral y enfatizan el cumplimiento de las fechas límite para la entrega de actividades. Su perspectiva (racionalmente limitada) sobre un buen desempeño se hace manifiesta.

Haciendo referencia general sobre los resultados de la actitud de los líderes del Centro Local Zulia, puede evidenciarse que mantienen buenas relaciones con su equipo de trabajo, los jefes buscan ajustarse a cualquier circunstancia laboral, trasmiten confianza a los empleados y seguridad en sus capacidades, aunque de igual forma establecen normas y tiempo para la realización de las actividades mediante un grado no muy elevado de influencia que ejerce sobre la actuación de los empleados. Esto permite concluir que la actitud del liderazgo en el Centro Local Zulia puede variar de acuerdo a las situaciones que se presenten (sistema flojamente acoplado). De aquí puede referenciarse lo que plantean Lussier y Achua (ob. cit) respecto a cómo la actitud del líder es un factor determinante en la formación de la cultura de la institución.

Ratificándose también la exposición de Daft (ob. cit) y Saracho (ob. cit), quienes señalan que una actitud es la consecuencia de los valores y normas que la preceden, dado su carácter adquirido, constituyendo a su vez es una tendencia evaluadora positiva o negativa con respecto a las personas, hechos o cosas. Las actitudes reflejan cómo se siente cada individuo con respecto a algo o a alguien y predice su tendencia a actuar de una manera determinada, dentro de un contexto específico en tanto se vinculan en mayor o menor 
proporción con los factores individuales y sociales que las estipulan. La data recopilada permite percibir en cierta forma, como acotan Cohen y March (ob. cit), la presencia de una anarquía organizada en la sede investigada.

\section{CONCLUSIONES}

El análisis del liderazgo de los Jefes de Unidad del Centro Local Zulia de la Universidad Nacional Abierta, con énfasis en la determinación de las funciones que cumplen y la identificación de la actitud de sus líderes, permitió identificar que la comunicación y la delegación se ubican en los valores promedios, visualizando la presencia de la información de forma oportuna. Se detectó que las relaciones interpersonales, las actitudes del personal y la motivación son adecuadas para cumplir con los objetivos y metas institucionales requeridas, pues existe cierto nivel de cohesión entre los elementos nombrados, situación que debe aprovecharse para defender el nivel de liderazgo y a su vez conservar una ambiente organizacional favorable que genere compromisos entre los actores involucrados.

En cuanto a la actitud de los líderes del Centro Local Zulia muestran ante el personal, se determinó que puede variar de acuerdo con las situaciones que se presenten, ya que se evidencia que los Jefes de Unidad mantienen buenas relaciones con su equipo de trabajo, buscan ajustarse a cualquier circunstancia laboral, trasmiten confianza a los empleados y manifiestan seguridad en sus capacidades, aunque también establecen normas y tiempo para la realización de las actividades asignadas.

Ante estos resultados, se propone a la institución realizar reuniones periódicas, en las cuales se planteen de manera seria y responsable los problemas presentes en la institución y puedan considerarlos como experiencia en su planeación y toma de decisiones en función de involucrar más a los empleados, a fin de mantener un clima consultivo, participativo, basado en la reflexión, con el propósito de obtener mayor productividad laboral y un buen clima organizacional. Si bien es poco probable que como organización deje de ser flojamente acoplada, dadas sus características intrínsecas, por lo menos debe intentarse que hagan su mejor esfuerzo para evitar que la limitación racional que los envuelve sea el ente que lleve la batuta de su desarrollo y desempeño. 


\section{REFERENCIAS}

Bateman, T. y Snell, S. (2001). Administración. Una Ventaja Competitiva. México: McGraw-Hill.

Chávez, N. (2007). Introducción a la Investigación Educativa. Maracaibo: ARS Gráfica, S.A.

Cohen, M. y March, S. (1974). Leadership and Ambiguity: The American College President. NewYork: McGraw-Hill.

Hernández, R.; Fernández, C. y Baptista, P. (2010). Metodología de la Investigación. 5a. Edición. México: McGraw-Hill.

Daft, R. (2006). La Experiencia del Liderazgo. México: Thomson Learning.

Da Silva, R. (2003). Teorías de la Administración. México: Thomson Paraninfo.

Davis, K. y Newstrom, J. (2003). Comportamiento Humano en el Trabajo. México: McGraw-Hill.

Lussier, R. y Achua, C. (2011). Liderazgo. Teoría, Aplicaciones y Desarrollo de Habilidades. México: Cengage Learning.

Madrigal, B. (2002). Habilidades Directivas. México: McGraw-Hill.

March, J. y Simon, H. (1958, 1977). Teoría de la Organización. Madrid: Ariel.

Mintzberg, H. (1991). Mintzberg y la Dirección. Madrid: Ediciones Días Santos.

Palella, S. y Martins, F. (2010). Metodología de la Investigación Cuantitativa. Caracas: Fondo Editorial de la Universidad Pedagógica Experimental Libertador (FEDUPEL).

Robbins, S. (2007). Comportamiento Organizacional. México: Prentice-Hall.

Saracho, J. (2005). Un Modelo General de Gestión por Competencias. Modelos y Metodologías para la Identificación y Construcción de Competencias. Santiago de Chile: RIL Editores.

Schermerhorn, J. (2010). Administración. México: Limusa Wiley.

Sierra Bravo, R. (1999). Técnicas de Investigación Social. Teoría y Ejercicio. Madrid: Paraninfo.

Simon, H. (1947). El Comportamiento Administrativo. Madrid: Aguilar.

Tamayo, M. (2003). El Proceso de la Investigación Científica. México: Limusa. 